\title{
The Use of a Commercial Textbook in English 1 Course at a University in South Korea
}

\author{
Adaninggar Septi Subekti \\ English Education Department, Duta Wacana Christian University \\ e-mail: adaninggar@staff.ukdw.ac.id
}

\begin{abstract}
:
This study investigated the use of a commercial textbook in English 1 Course at a university in South Korea seen from the framework of a sound curriculum development. Thus, the use of a commercial textbook was analysed and evaluated in relation to elements of curriculum development, such as needs analysis, learning aims, syllabus, methodology, and materials, as well as assessments. It was found that the use of the textbook drove what were taught in the whole course and thus practically "functioned" as its syllabus. However, it was found that the textbook could not facilitate learners to achieve all of the learning aims of English 1 course and it contributed to a disparity of learners' achievements across different classes. Furthermore, the reading assessment, derived from the textbook, was unable to assess learners' achievements in all of the learning aims of English 1 course. Thus, it is suggested that teachers form informal workshop groups among teachers where they can share problems they face in class and possible solutions on how to address them in areas within their control. Based on the results of the study as well as the limitations, some recommendations for future studies are also presented.
\end{abstract}

Keywords: commercial textbook, English 1 Course, curriculum, syllabus 


\section{Introduction}

\subsection{Backgrounds}

English education is not something new in South Korea and among Asian countries, South Korea has had great inroad of English in its educational systems (Choi \& $\mathrm{H}$. W. Lee, 2008). Even, Flattery (2007) noted that South Korean youngsters are required to start learning English at a younger age. In fact, it has been 134 years of systematic English education in South Korea since its initiation in 1883 (Min, 2013). Furthermore, since the country's first national curriculum was introduced in 1955 (B. M. Chang, 2009), in the last three decades, English is getting more popular and is widely seen as one key success (Jeon, 2015; Kang, 2012; Tudor, 2012). The growing popularity of English among South Koreans is highly influenced by three major reasons, namely government policies, social and economic changes, as well the growing popularity of communicative teaching methods (J. K. Park, 2009).

Furthermore, English growing popularity can also be seen in the growing number of classes at universities taught in English, or known as English as Medium Instruction (EMI) programs, since the early 2000s (Byun, Chu, M. Kim, I. Park, S. Kim, \& Jung, 2011). With regard to this, the South Korean government's incentives that are given to the universities employing EMI modules may be one of the supporting factors of the trends of EMI among universities (Byun et al., 2011). Hence, to prepare Korean students for the EMI modules in their respective majors, universities provide students with introductory English intended for freshmen students (Byun et al., 2011) in which universities usually conduct such classes differently from one another. Some universities might have English preparation classes consisting of two levels; some others might have three-level classes. Students are required to pass these classes to prepare themselves for content classes taught in EMI modules in their respective majors or disciplines.

Specifically about the university whose English preparation course will be analysed, furthermore, there are two English courses, Level 1, focusing on reading and discussion, and Level 2, focusing on reading and writing. Both of the courses are compulsory for new students as they serve as students' preparation for EMI modules in their majors. Native English speaker teachers teach these classes, which were organized by local course administrators.

\subsection{Rationales}

In relation to the above-mentioned phenomena of the English classes for nonEnglish majored university students in South Korea, many universities in Indonesia, regardless of their having EMI modules, have also been conducting relatively the same types of classes as the above-mentioned English preparation classes. In Duta Wacana Christian University (UKDW), where I work, for example, all undergraduate students are required to pass three levels of Introduction of College English (ICE), which are non-credited, to be able to take English for Specific Purposes (ESP), which are credited, in their respective majors. Hence, to obtain a perspective of an ELT practice in another country may be beneficial for Indonesian 
ELT practitioners, especially those teaching English to non-English university students.

Secondly, some universities in Indonesia might have their own modules for such classes, while some others might use commercial textbooks as the main sources of materials and instructions. Regarding the latter, Richards (2001) commented that the use of commercial textbooks in a language program has both advantages and disadvantages. It depends on how the textbooks are used and on the contexts of the use (Litz, 2004). Hence, to evaluate the use of commercial textbooks in an English program is very important as well.

Furthermore, among other issues in ELT, issues in the curriculum have always been paramount important. A good curriculum is the implementation of a course or a program and a good curriculum development includes many processes that need to be done before, during, and after a language program is conducted (Richards, 2001). They are processes used to determine the needs of learners, to develop aims or objectives for a program to address those needs, "to determine an appropriate syllabus, course structure, teaching methods, and materials, and to carry out an evaluation of the language program" (Richards, 2001, p. 2). Thus, it is also important to evaluate the use of commercial textbooks in language programs in the framework of a good curriculum development. This might also serve as a part of curriculum evaluation as well.

\subsection{Research Questions}

Considering the rationales mentioned above, this study aimed to answer the following research questions:

1. To what extent is the use of a commercial textbook in English 1 course?

2. How is the use of a commercial textbook in English 1 Course at the university seen from the framework of a sound curriculum development?

\section{Literature Review}

The term "curriculum" comes from a Latin word, which has the meaning of "racing chariot". That may imply that it is a way to get from one place to another in a fast and effective manner. In educational practices, the curriculum includes what learners learn, "how they learn it, how teachers help them learn using what supporting materials, styles, and methods of assessment, and in what kind of facilities" (Rodgers, 1989, p. 26). Even viewed from the field of applied linguistics, the definition of curriculum is relatively the same. Richards, Platt, and Platt (1992) stated that a curriculum is an educational program, which states the purposes, the means to achieve the purposes, such as contents, teaching procedures, and some means of assessing whether or not the purposes of the program has been successfully achieved.

In relation with that, furthermore, Masuhara (2011) mentioned that the actual sequence of curriculum development includes planning, implementation as mentioned above, and evaluation. It starts from needs analysis, objectives, syllabus, 
methodology, assessment, and ends with evaluation (Masuhara, 2011). Hence, it can also be stated that this interrelated system of elements is known as curriculum.

Firstly, needs analysis are procedures to collect information about learners' needs (Richards, 2001). Richards (2001) further stated that needs analysis serves several purposes. This includes to find out learners' skill levels, to know learning problems learners are experiencing as well as to identify a gap between what learners already know and what they need to know. Richards (2001) stated that conducting needs analysis is very important in any curriculum development, as "a sound educational program should be based on analysis of learners' needs" (p. 51). Based on the needs analysis, course objectives can be obtained.

To be more specific, course objectives refer to what learners are expected to be able to do upon the completion of the course (Masuhara, 2011). In other words, objectives tell about the goals of the course or the improvements of the competency level expected from learners from before they take the course until the time they complete the course. Furthermore, even though intuitively speaking, some people may state that learning objectives and learning aims or goals are different in the way that aims are more general than objectives, in curriculum development framework, these terms are in the same position and thus can be used interchangeably.

A syllabus, furthermore, shows the contents of the given course (Rodgers, 1989). It describes "the major elements that will be used in planning a language course and provides the basis for its instructional focus and content" (Richards, 2001, p. 152). Simply put, a syllabus tells what is taught in a course or a program.

Specific about the syllabus, some authors mentioned several types of syllabus even though in practice, a syllabus is very often the combination or integration of various types of syllabuses (Brown, 1995; D. Willis, 1990; Richards, 2001). First, a syllabus can be divided into product syllabus, which focuses on the product of learning, and process syllabus, which focuses on the ways (methods) of achieving these ends. Process syllabus can be in the form of a task-based syllabus, a negotiated syllabus, and a post-modern syllabus. Product syllabus, furthermore, can be divided into a synthetic syllabus, emphasizing careful controls on the order and manners in which linguistics items are introduced to learners, and an analytic syllabus, which presents learners with chunks of language as they naturally occur in life (Richards, 2001). Furthermore, a synthetic syllabus can be in the form of formal syllabuses such as grammatical, lexical, phonetic, and discoursal syllabus, and functional, which can be in the form of function, notion, and social interaction (D. Willis, 1990). Analytic syllabus, furthermore, can be in the form of the situational, skill-based, contentbased, or text-based syllabus (Brown, 1995).

Specific to the contents of the course, furthermore, commercial textbooks become ones of the most common forms of teaching materials (Richards, 2001). In fact, many authors pointed out the benefits of using textbooks. Haycraft (1998), for example, stated that textbooks are psychologically essential for students to measure their progress and achievement. Even some students think that textbooks have more credibility than teachers-generated materials (Sheldon, 1988). Furthermore, using 
textbooks is deemed more practical and inexpensive, and thus this allows both teachers and the institution conducting the language program to invest their time and resources for other pursuits as well (O’Neill, 1982; Sheldon, 1988).

Richards (2001), however, warned that despite the vast uses of commercial textbooks in teaching programs and the possible advantages, commercial textbooks also possess some potential disadvantages. These include the inauthentic language some textbooks may contain and that the textbooks may not reflect learners' needs. In addition, they can also deskill teachers as heavy usage of textbooks may reduce teachers' creativity and instructional decisions (Richards, 2001). This is attributed to the possibility that teachers who teach classes with a commercial textbook tends to stick with the textbook the whole time and it may potentially reduce teachers' efforts in varying instructional decisions in class.

Concerning the use of textbooks, Cunningsworth (1995) proposed four criteria to evaluate textbooks. The use of textbooks should meet learners' needs, reflect the language learners will prospectively use, facilitate learners' learning process and have a clear role as support for learning. Simply put, Cunningsworth (1995) suggested that a good textbook should be in accordance with the needs of learners using it and it should facilitate them to achieve the goals of the course.

To be more specific, furthermore, Nation and Macalister (2010), mentioned seven criteria on how a textbook can be evaluated. The first is whether the course book suits the environment in which it will be used. The second is whether a course book meets the needs of the learners. The third is whether the course book applies sensible principles of teaching and learning. The fourth is whether the goals of the course book match the goals of the course. The fifth is whether the content of the course book suit the proficiency level of the learners and reflect sensible selection and sequencing principles. The next is whether the course book interesting and uses techniques. The last is whether the course book includes tests and ways of monitoring progress.

Furthermore, Nation and Macalister (2011) held the opinion that "a single course book does not meet the diverse needs of learners in the class" (p. 163). Besides, the various contexts under which certain textbooks are used make selecting appropriate textbooks quite difficult (Nation \& Macalister, 2010). Hence, they suggested that teachers use various sources, instead of solely use a course book, to meet learners' various needs in class.

The above-mentioned critical voices directed towards specific aspects of curriculum are based on the realisation that "a curriculum, like a recipe for a dish, is first imagined as a possibility, then the subject of experiment" (Stenhouse, 1975, p. 4). A curriculum needs an evaluation as it is a very important step in a curriculum development to find out how successful a course has been conducted (Weir \& Roberts, 1994). Specifically, Weir and Roberts (1994) stated that language program evaluation serves two main purposes, which are program accountability and program development. Evaluations with an accountability orientation focus on the effects, or the products of a program. Evaluations with development orientation, by 
contrast, focus on the improvements that can be done to a program while it is being implemented (Weir \& Roberts, 1994).

Two most common types of evaluations are formative and summative. Richards (2001) stated that formative evaluation is carried out "as part of the process of program development in order to find out what is working well, and what is not, and what problems need to be assessed." (p. 288). It is also based on the realisation that curriculum design does include "ongoing evaluation of the course" (Nation \& Macalister, 2010, p. 11). Hence, this type of evaluation is conducted in the middle of the implementation of the program. Summative evaluation, by contrast, focuses on the effectiveness of a program (Richards, 2001). As such, it is usually conducted at the end of the program.

Furthermore, as mentioned above, curriculum evaluation is necessary because "once a curriculum is in place, a number of important questions still need to be answered" (Richards, 2001: 286). Quality teaching is obtained as not only the consequence of teachers teaching well in class but also through "contexts and work environments that can facilitate good teaching" (Richards, 2001, p. 198). As such, curriculum evaluations include not only aspects directly related to teaching but also aspects outside class, such as teachers' work environments and the overall organizational structure of the institution conducting the program. This can include the culture and environment existing within a school or a university, the kinds of communications among people within, and its management system and structure (Richards, 2001).

With regard to this, Davidson and Tesh (1997) emphasized that the basis of the organizational structure of an institution is the management structure. This includes authority relationships, communication networks, specific planning as well as organizational techniques. They further stated that there are two types of organizational structure, namely mechanistic model, and organic model and that most language programs have the features of both models. The mechanistic model emphasized on authority, a hierarchy of control, and chained of commands (Davidson \& Tesh, 1997). In practice, that allows administrators to give clear guidance of uniformity for teachers in class. For examples, administrators select teachers to teach specific classes based on their expertise and provide detailed syllabus telling teachers specific contents that should be covered each day and specific tasks that should be given for assessments. Organic model, in comparison, is characterized by flexibility and adaptability. It encourages trust and confidence between superiors and the subordinates. Subordinates can communicate ideas to the superiors quite easily. Thus, decision-making and controls are relatively shared among people within the organization (Davidson \& Tesh, 1997). Each model of organizational structure has its own merits towards the implementation of a language curriculum as a whole if implemented in the appropriate conditions (Davidson \& Tesh, 1997).

Specific about universities in South Korea, furthermore, many university administrators in Korea usually emphasize not only traditional norms and values but also hierarchical order and authority (J. K. Lee, 2000). That is to say that they normally use strict leadership and allow very little subordinates' participation as 
well as discussion in decision-making (Tudor, 2012). J. K. Lee (2000) argued that this culture stems from Confucianism or Japanese Shinto - Confucianism, both of which have a long history in South Korea. Hence, with regards to Davidson and Tesh's (1997) models of organizational structures that can affect curriculums, it is likely that South Korean universities tend to assume the mechanistic model much more than the organic model.

\section{Research Methodology}

\subsection{Rationales for the Methods}

This study used two methods, secondary data analysis, and interview. The first was an interview with a native speaker teacher of English 1 at the university. The second was a document analysis on the documents used in the English 1 course. These included the commercial textbook used and the course booklet. These two methods were conducted simultaneously, in which the interview participant gave information about his experience during his period of teaching at the university. The information from the participant was used to enrich the data obtained from the secondary data analysis. Through the help of the participant's colleagues who were working at the university, some additional data on how they managed their English 1 class were obtained. The whole data collection was conducted during the period of October 2015 - December 2015.

Secondary data analysis refers to analysing the already existing data, which had been collected or made for other purposes (Gray, 2014). The advantages of using such data include the efficiency in time and money in not having to undertake a primary research. However, the disadvantage that the data may be inaccurate and obsolete to be used to answer the research question. That was exactly why the interview was conducted simultaneously with the secondary data analysis. Besides aimed at investigating how the English 1 course was conducted through the viewpoints of the participant, which might not be captured in the documents, the interview also served as a means to triangulate the data obtained through secondary data analysis (Bryman, 2004). In other words, while I, the researcher, analysed the secondary data such as the textbook and the course booklet, the participant gave information about what I need to know such as affirmation and clarification of my data analysis, and his subjective opinions on certain issues in English 1 course. As interviews value subjective analysis of realities (Bryman, 2012; Punch, 2014) and allow the investigation of a phenomenon through the eyes of the participant (Bryman, 2012; May, 2001), these possible subjective opinions from the participant are not seen as weaknesses of the study. Instead, they are treated as valuable data through the participant's viewpoints.

With regard to the presentation of findings and discussion, furthermore, unless explicitly stated, all data reported were obtained from the secondary data analysis. Hence, data collected from the secondary data and interview could be easily distinguished. 


\subsection{The Participants and some Ethical Considerations}

An English program at a Korean university was chosen because it was intended to give readers a different perspective of an ELT issue in another Asian country. In South Korea, English is also used as a foreign language. Hence, the use of English in South Korea may not be so different from that in Indonesia. The participant was a native speaker teacher at the university whose language course was analysed. The name of the participant and the university were both kept confidential as the acknowledgment of the importance of confidentiality in research (Israel \&Hay, 2006). As such, the name of the university was not disclosed throughout this paper. Similarly, regardless of the exact name of the language course, the term "English 1" was used throughout this paper to refer to Level 1 program and the title of the textbook used was not disclosed either to avoid the possibility of the name of the university being identifiable. Furthermore, the participant willingly participated without any coercion (Oliver, 2003).

\section{Findings and Discussions}

\subsection{Research Question 1: To what extent is the use of a commercial textbook in English 1 course?}

Firstly, the single textbook for English 1 course, according to the participant, in practice drove what was taught in English 1 course. Thus, in relation with Richards' (2001) statement saying that a syllabus basically tells about what is taught or the basis for all of the instructional focus and content, considering what happened in practice based on the participant's testimony, it could be said that practically the textbook "functioned" as syllabus (Richards, 2001).

Furthermore, English 1, as seen in the course booklet, was designed to help students develop reading and speaking skills with special emphasis on the following:

1. reading skills,

2. study skills,

3. vocabulary,

4. discussion skills, and

5. critical thinking

Considering the above-mentioned five-course aims, it was expected that the university's English 1 had an integrated syllabus, combining elements of different types of the syllabus (Richards, 2001). First, it was supposed to have a product analytic, skills-based syllabus (Brown, 1995; Johnson, 1995), focusing on skills. Then, it was also supposed to have a product synthetic lexical syllabus (D. Willis, 1990) focusing on vocabulary. Considering the aims on the discussion as well as critical thinking skills, furthermore, it was also expected that it had a process syllabus requiring the use of many communicative activities in that of Communicative Language Teaching (CLT) (Harmer, 2007) or series of task through which learners learn the language in Task-Based Learning (TBL) (J. Willis \& D. Willis, 1996). 
Even though textbooks and syllabus are two very different things, considering that the commercial textbook used in English 1 course practically "functioned" as syllabus, it became relevant to evaluate the textbook "as" syllabus as well. A part of the next section on research question 2 below will explain this further.

\subsection{Research Question 2: How is the use of a commercial textbook in English 1 Course at the university seen from the framework of a sound curriculum development?}

\subsubsection{The commercial textbook was unable to facilitate learners achieve all of English 1 course's objectives/learning aims}

Nation and Macalister (2010, p. 165), mentioned seven criteria on how a textbook can be evaluated. Comparing the course aims, seen in the course booklet, and the contents of the textbook, it was found that this textbook failed in fulfilling two criteria of a good textbook. Those were criteria number two, whether the textbook meets the needs of learners and number four, whether the goals of textbook match the goals of the course.

The first was that the textbook did not meet the learners' needs for EMI preparation requiring communicative tasks. EMI programs, needless to say, necessitate learners to communicate their ideas in their respective disciplines in English, and as such English preparation programs are supposed to prepare them by giving more communicative activities. The English 1's textbook, however, did not have enough communicative contents.

Secondly, while it could help learners achieve the above-mentioned aims number 1 , 2 and 3, on reading skill, study skill, and vocabulary, respectively, it could not facilitate learners to achieve the fourth and fifth aim, discussion skills and critical thinking respectively. Therefore, referring to types of syllabus presented earlier, while the textbook fulfilled product syllabus, both analytic and synthetic, it did not fulfil process syllabus, which required communicative activities to help students achieve aim number 4 on discussion skill and number 5 on critical thinking.

Considering these two aims, furthermore, highly communicative activities in class were needed. Unfortunately, there were few elements of communicative activities found in the textbook used. It could clearly be seen through analysing the contents of the textbook's chapters. There was only one section, focusing on communicative activities, out of six in every single chapter. In other words, it was only $17 \%$ of the textbook's contents, which facilitated learners to speak. Ideally, the textbook should have approximately $40 \%$ communicative content of the overall content of the textbook to accommodate the two aims, on discussion skill and critical thinking, which focus on oral communication. From the following figure, it was clear that the textbook did not reflect all aims of the course. 


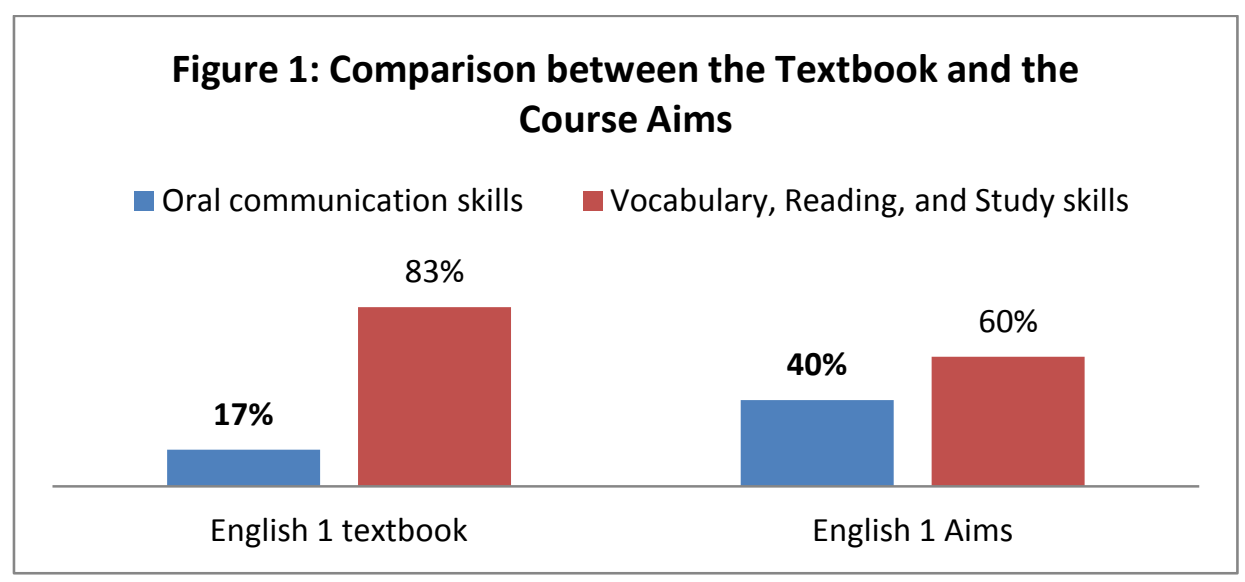

Furthermore, the participant commented that, because of the administrators selecting a commercial textbook after developing the course's learning aims, they skipped needs analysis process, which is actually paramount important to investigate the learners' lack and needs (Nation \& Macalister, 2010). Obviously, skipping this process made them unable to consider the learners' need in terms of meeting aims on discussion skills and critical thinking. The participant, to be more specific, stated that the administrators did not use the results of the English test conducted at enrolment process to allocate freshman students in appropriate levels of English preparation classes. In fact, tests conducted before enrolment could be used as placement tests and according to Brown (1995), these tests are important to investigate learners' lack, and to allocate students to the class of appropriate level (Hughes, 2003; Kitao \& Kitao, 1999). As the participant stated, the result of not using any appropriate placement tests was that almost all classes consisted of students of mixed ability levels. Regarding this, Harmer (2007) warned that teaching class consisting of students various language levels became one of the biggest problems teachers face (Harmer, 2007) as generally, teachers teach better when students are approximately at the same level of competence (Brown, 1995). At the end, these mixed-ability classes may contribute to teachers' being unable to help learners meet all the teaching aims optimally.

Furthermore, the following English 1's teachers' testimonies obtained via email may better illustrate what happened in English 1 classes in relation with the commercial textbook's deficiencies in facilitating learners to meet all of the course aims.

"I don't give a great deal of thought to meeting them [the aims]. But there certainly are a lot of communicative aspects to our classes, but being based on the textbook discussions, they probably don't qualify as 'critical thinking'." (Teacher 1)

"I would say that meeting objectives [aims] $4 \& 5$ is probably what makes up most of my classes. I do many group tasks, usually only very loosely related to the stuff in the textbook. In English 1 I like to do at least one group presentation each semester, which I use to calculate their participation score." (Teacher 2) 
As could be observed from the testimony of Teacher 1 , even the communicative elements in the textbook were said to be unable to stimulate the students' critical thinking and the teacher gave little efforts in helping learners meet the course aims at discussion skills and critical thinking, all of which were not accommodated in the textbook. In comparison, Teacher 2 commented that he designed his own additional materials and class activities that could help learners achieve the two-course aims, which would not have been accommodated if he had only relied on the textbook.

Furthermore, as the participant commented, the use of the textbook also directed the type of assessment of English 1 course. The assessments, mid-term and final exams, were in the form of close-ended reading tests. As achievement assessment aims to know how much students have achieved the aims of the course (Brown, 2005; Hughes, 2003), these reading assessments might not have content validity (Child, 2007; Hughes, 2003; Marsh, 1992) because they did not measure all of the course aims. Based on the course aims, especially on discussion skills and critical thinking, English 1 necessitated direct assessment (Hughes, 2003) in the form of performance tests, in which learners could demonstrate useful functions and meaningful language (Brown, 2005). Hence, reading assessments based on the textbook might not be sufficient to assess whether learners had achieved all of the aims of the course.

\subsubsection{The use of commercial textbook was attributed to potential disparity of learners' achievements}

It is interesting that despite mentioning the ideal sequence of curriculum design procedure starting from needs analysis, aims, syllabus, methodology, assessment, and ending with evaluation, Masuhara (2011) also mentioned that the actual sequence many ELT practitioners experience all over the world is that administrators select materials from commercial textbooks after deciding the aims of their courses.

The comparison could be seen in the following figures.

Needs Analysis Goals and Objectives

\section{Syllabus Design}

Methodology/Materials Testing and Evaluation

Figure 2: 


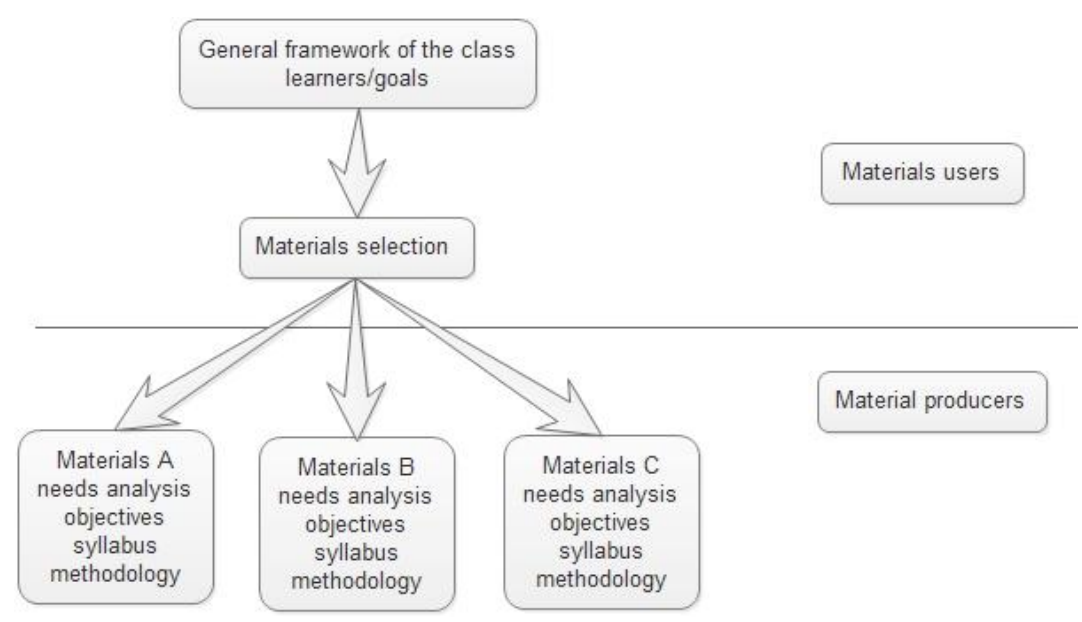

Figure 3: Curriculum design in common practice (Masuhara, 2011, p. 249)

Interestingly, what is shown in Figure 3 above, which according to Masuhara (2011) has happened in many places, was exactly what the English 1's administrators at the university did. Hence, one interesting question surfacing was that if what happened at the university also happened in many other places, why it was such a big problem to have a textbook that practically "functioned" as the syllabus.

The urgency of the problem caused by the use of a single commercial textbook driving the whole English 1 course, thus practically "functioning" as syllabus, at the university was also closely related to its overall organizational structure, having some features of both organic and mechanistic model (Davidson \& Tesh, 1997) with "half-hearted" implementation. For example, it had the textbook as the guidance of uniformity in terms of materials. However, it did not facilitate aim 4 and 5 as previously mentioned. What was worse, based on the participant's testimony, teachers were not provided with any single guidance on how to compensate the textbook's deficiency in relation to the aims of the course. In other words, these teachers were given freedom on how to address this issue in class. In addition, there was no training for this either. Moreover, the participant commented that the hierarchical structure of the university organization allowing very little communication among peer native speaker teachers and among teachers and the local administrators could worsen the issue of high freedom with little guidance mentioned earlier. It, eventually, may result in uncertainties in teaching performance, especially the teachers' teaching methodologies. This "freedom" might also contribute to the various methodologies that the teachers used in class as partly reflected in the testimonies of the Teacher 1 and Teacher 2 presented above, in which while one teacher tried hard to help learners meet all of the aims of the course, the other teacher was already "comfortable" using the textbook all the time despite its deficiency in facilitating learners to achieve learning aims number 4 and 5. 
As the consequence of this textbook's deficiency, furthermore, teachers should compensate this in such a way to meet the oral communication aims with all the freedom given by the course administrators (Goh \& Burn, 2012) However, while teachers might adopt, adapt and develop (Brown, 1995; Nation \& Macalister, 2010), in such situation where there is no detailed syllabus, teaching methods used by teachers might become uncertain (Richards, 2001).

Let us pay attention to the testimonies of Teacher 1 and Teacher 2 in the previous section once again. These excerpts, while could be seen from the angle of textbook's deficiency in facilitating learners to meet all of the course aims, could also be seen from the angle of various teachers' methodologies. Teacher 1 taught what was in the textbook only, while Teacher 2 gave supplementary materials and activities to help learners meet all of the course aims, two of which were not facilitated in the textbook. In other words, while some students from some classes in English 1 might get much exposure to communicative activities and obtain enrichment materials from their teachers, other students from some other classes might merely be taught what was in the textbook. In addition, the participant confirmed this as well. With regard to this, Ganyaupfu (2013) warned that a course or program in which teachers employ different methods in different classes might lead to disparity in students' achievements across different classes. Thus, upon the completion of English 1 course, some English 1's students who obtained enough exposure to communicative activities in class might be able to communicate better than their counterparts who did little communicative activities due to their teachers' sticking to the textbook all the time.

\subsection{Recommendations for Changes and the Possible Challenges}

Furthermore, considering the big impacts of the use of a single commercial textbook on curriculum as a whole, one might consider recommending some changes. The most straightforward recommendation might be not to use a single commercial textbook, which might not facilitate learners to meet all of the course aims. To suggest the English 1's administrators to do the ideal sequence of curriculum development, from conducting needs analysis, determining learning aims, determining syllabus, and methodology as well as conducting assessments and evaluations in sequence (Masuhara, 2011) could also be a possibility.

However, while recommendations for changes may work in some contexts, they may not work in some other contexts. At the university, as the participant commented, directly recommending changes might be quite difficult. It was attributed to some reasons. The university, just like typical Korean universities, had a top down hierarchical structure of organization deeply rooted from Korean culture (J. K. Lee, 2000; Tudor, 2012). It allowed very little communications with little room for discussions, especially directly giving direct suggestions to superiors. Thus, awareness of this issue from the local administrators in charge of managing the course might be a straightforward way of implementing changes in the course.

Alternatively, native speaker teachers could also set up teachers' informal workshops followed with working groups. The workshops could function as a place 
for peer teachers' discussions (Crookes, 2003; Richards, 2001). Workshops along with working groups can give some clear advantages (Nation \& Macalister, 2010). They could be forums in which teachers can identify problems and establish common awareness for the need of change (Nation \& Macalister, 2010), shared decision-making (Pennington \& Hoekje, 2010; Richards, 2001), and "cohesive teaching force with good team spirit" (Richards, 2001, p. 201). They can also be a means towards teacher empowerment (Marsh, 1992) and professional growth (Brown, 1995). In relation with English 1 course, furthermore, in the workshops, teachers could form small working groups to identify problems on English 1 course, and work on how to help students meet all the aims of the program that the textbook could not fully facilitate, through areas within their control in the classroom, including methodologies and assessments. These teachers' efforts might eventually help English 1 students achieve all the aims of the program despite the textbook's deficiency.

Related to content validity issue of the assessments presented previously, specifically, the working groups could introduce speaking tests along with the already existing reading tests as speaking tests could help make the whole assessment measure all of the aims of the course, and thus have content validity (Brown, 2005; Child, 2007). For the sake of practicality, however, they might need to make the speaking test in group presentation format as this would allow both discussions on issues as well as critical thinking in preparation for EMI courses (J. Y. Chang, W. Kim, \& H. Lee, 2015).

However, it should be realized that setting up workshops and working groups, despite all merits mentioned above, is not without challenge. Considering they are conducted informally, there will be no incentives given for teachers by the university in doing the extra works. Hence, teachers are required to go out of their comfort zone of being paid after teaching using provided textbook. It is not always easy to do that. Realistically, some teachers might possibly feel reluctant to get involved as it does mean extra work without extra money. However, if the teachers realise the importance and benefits of the workshops and working group, while the barrier is not going to be easy to overcome, this will not be impossible to conduct either.

\section{Conclusions}

\subsection{Summary}

As the conclusion, some points could be summarized. The English 1's local administrators selected a single commercial textbook to be used for the course, and in practice, the textbook had driven what was taught in the whole course, thus "functioning" as the syllabus. This, in turn, led to some issues. First, the textbook was unable to facilitate learners to achieve all of the course aims. Out of the five aims, the textbook could only facilitate learners to achieve three aims. Furthermore, as there was no guidance from the local administrators on how the teachers should address this issue in class, teachers were given "freedom" whether to stick to the textbook the whole time or give supplementary materials and communicative 
activities in class. Hence, this resulted in the disparity of students' achievements throughout the different classes. Moreover, being based on the textbook, the closeended reading assessment conducted in the middle and at the end of the semester, also failed to assess all of the learning aims as the reading tests could not assess two learning aims, discussion skills, and critical thinking, which necessitated productive aspects, such as speaking.

Finally, it is argued that collective teachers' initiatives could help remedy the situation in the areas within their authority, like methodologies and assessments. It is fully realised that curriculum design does include "ongoing evaluation of the course" (Nation \& Macalister, 2010, p. 11), and thus, it is open to adjustment in the process. Therefore, despite various factors outside classroom affecting curriculum (Saylor, Alexander, \& Lewis, 1981) of the university's English 1, as the final decision makers concerning learners' actual learning opportunities, teachers can still do many things within their control to optimize their students' learning, including through cooperating with fellow teachers.

\subsection{Limitations}

This study investigated a language program in which I, as the researcher, was not involved. While this could keep any possible bias to the minimum as the advantage, this could also become a limitation. While the English 1 course documents could be analysed whether or not the researcher was part of the program, some information related to how the program was conducted in more detailed could only be obtained through interviewing the participant, who was a teacher of English 1 course. Thus, this was quite impractical. Secondly, this study did not include the English 1 course's local administrators as the participants. Hence, the perspectives presented in this study were limited to those of the teachers. In addition, the qualitative methods conducted in the study carried the consequence that the results of this study might not be generalised to a wider population.

\subsection{Future Studies}

In the light of the results of the study and the limitations mentioned above, future studies could consider the following suggestions. First, it may be worthwhile to evaluate language programs in our own departments or institutions and investigate the core problem in their curriculum. First, it is practical to conduct, and it will be beneficial for the institution where the researchers work. Secondly, future studies may include teachers, students, and administrators of the language program as the participants to obtain perspectives from various parties involved in the language program. Finally, specifically investigating teachers' initiatives in helping learners achieve all of the learning aims in class can be very important as well.

\section{References}

Brown, J. D. (1995). The Elements of Language Curriculum. Boston, MA.: Heinle, Chengage Learning.

Brown, J. D. (2005). Testing in Language Programs: A Comprehensive Guide to English Language Assessment. New York: McGraw-Hill. 
Bryman, A. (2004). Triangulation. In Lewis-Beck, A. Bryman, \& T. F. Liao, Encyclopedia of Social Science Research Methods (pp. 1143-1144). Thousand Oaks: SAGE Publications, Inc.

Bryman, A. (2012). Social Research Methods (4th Edition). Oxford: Oxford University Press.

Byun, K., Chu, H., Kim, M. [Minjung], Park, I. [Inwoo], Kim, S. [Suhong], \& Jung, J. (2011). English-medium teaching in Korean higher education: policy debates and reality. Higher Education, Vol. 62, No. 4 (October 2011), 431449.

Chang, B. [Bok-Myung] (2009). Korea's English education policy innovations to lead the nation into the globalized world. Journal of Pan-Pacific Association of Applied Linguistics, 13(1), 83-97.

Chang, J. [Ji-yeon], Kim, W. [Wooyeon], \& Lee, H. [Heewon] (2015). International Journal of Bilingual Education and A language support program for Englishmedium instruction courses: Its development and evaluation in an EFL setting. International Journal of Bilingual Education and Bilingualism, 0050, DOI: 10.1080/13670050.2015.1080658.

Child, D. (2007). Psychology and the Teacher. New York: Continuum International Publishing Group.

Choi, Y. H., \& Lee, H. W. [Hyo Woong] (2008). Current trends and issues in English language education in Asia. The Journal of Asia TEFL, 5(2), 1-34.

Crookes, G. (2003). A Practicum in TESOL: Professional Development Through Teaching Practice. Cambridge: Cambridge University Press.

Cunningsworth, A. (1995). Choosing your coursebook. Oxford: Heinemann.

Davidson, J., \& Tesh, J. (1997). Theory and practice in language program organization design. In M. A. Christison, \& F. Stoller, A Handbook for Language Program Administrators (pp. 177-198). Burlingame, CA: Alta Book Center.

Flattery, B. (2007). Language, culture, and pedagogy: An overview of English in South Korea. Retrieved May 22, 2017, from http://homes.chass.utoronto.ca/ cpercy/courses/eng6365-flattery.htm

Ganyaupfu, E. (2013). Teaching methods and students' academic performance. International Journal of Humanities and Social Science Invention., 2(9), 2935.

Goh, C., \& Burn, A. (2012). Teaching Speaking: A Holistic Approach. Cambridge: Cambridge University Press.

Gray, D. E. (2014). Doing Research in the Real World (Third Edition). London: Sage Publications, Ltd.

Harmer, J. (2007). How to Teach English. Edinburgh: Pearson Education Limited.

Haycraft, J. (1998). An Introduction To English Language Teaching. Essex: Longman.

Hughes, A. (2003). Testing for Language Teachers (Second Edition). Cambridge: Cambridge University Press.

Israel, M., \& Hay, I. (2006). Research Ethics for Social Scientists. London: Sage Publications. 
Jeon, M. (2015). Globalization and native English speakers in English Programme in Korea (EPIK). Language, Culture, and Curriculum, 22:3, 231-243, DOI: 10.1080/07908310903388933.

Johnson, K. (1995). Language Teaching and Skill Learning. Oxford: Basil Blackwell.

Kang, J. (2012). Teaching and Learning Culture in Korea's English as a Foreign Language Classroom. Edmonton, Alberta: University of Alberta.

Kitao, K., \& Kitao, K. (1999). Essentials of English Language Testing. Tokyo: Eichosha Co., Ltd.

Lee, J. [Jeong-kyu] (2000). The administrative culture and systems of Korean higher education. Journal of the programme of institutional management in higher education, 12(1), 43-51.

Litz, D. R. (2004). Textbook evaluation and ELT management: A South Korean case study. Asian EFL Journal, 1-53.

Marsh, C. J. (1992). Key Concepts for Understanding Curriculum. London: The Falmer Press.

Masuhara, H. (2011). What do teachers really want from coursebooks? In B. Tomlison, Materials development in language teaching (2nd Edition) (pp. 239-260). Cambridge: Cambridge University Press.

May, T. (2001). Social Research: Issues, Methods, and Process (Third Edition). Buckingham: Open University Press.

Min, K. E. (2013). English Speakers in Korea: A short literary history. In L. G. Wee, The Politics of English: South Asia, Southeast Asia, and the Asia-Pacific (pp. 269-286). Amsterdam: John Benjamins Publishing Company.

Nation, I., \& Macalister, J. (2010). Language Curriculum Design. New York: Routledge.

Oliver, P. (2003). The Student's Guide to Research Ethics. New York: Open University Press.

O'Neill, R. (1982). Why use textbooks? ELT Journal, 36(2), 104-111.

Park, J. K. [Jin Kyu] (2009). English fever' in South Korea: Its history and symptoms. English Today, 25(1), 50-57.

Pennington, M., \& Hoekje, B. (2010). Language program as ecology: a perspective for leadership. RELC Journal, 41(3), 213-228.

Punch, K. F. (2014). Introduction to Social Research: Quantitative and Qualitative Approaches. London: Sage Publications Ltd.

Richards, J. C. (2001). Curriculum Development in Language Teaching. Cambridge: Cambridge University Press.

Richards, J. C., Platt, J., \& Platt, H. (1992). Longman Dictionary of Language Teaching and Applied Linguistics. Harlow: Longman.

Rodgers, T. (1989). Syllabus design, curriculum development, and policy determination. In R. K. Johnson, The second language curriculum (pp. 24-34). New York: Cambridge University Press.

Saylor, J., Alexander, W. M., \& Lewis, A. J. (1981). Curriculum Planning for better Teaching and Learning (Fourth Edition). Tokyo: Holt-Saunders Japan. 
Sheldon, L. (1988). Evaluating ELT textbooks and materials. ELT Journal, 42(2), 237-246.

Stenhouse, L. (1975). An Introduction to Curriculum Research and Development. London: Heinemann.

Tudor, D. (2012). Korea: The Impossible Country. Tokyo: Turtle Publishing.

Weir, C., \& Roberts, J. (1994). Evaluation in ELT. Oxford: Blackwell.

Willis, D. [Dave] (1990). The Lexical Syllabus: A New Approach. Birmingham: Collins Cobuild.

Willis, J. [Jane], \& Willis, D. [Dave] (1996). Challenge and Change in Language Teaching. Oxford: Macmillan Heinemann English Language Teaching. 